\title{
The Australian Aged Care and Its Implications for the Korean Aging Crisis
}

\author{
Moo-Young Kim¹, Premala Subramaniam², Leon Flicker, \\ ${ }^{1}$ Department of Family Medicine, Seoul Medical Center, Seoul, Korea, ${ }^{2}$ Department of General Medicine, Hospital Kuala Lumpur, Kuala \\ Lumpur, Malaysia, ${ }^{3}$ Department of Geriatric Medicine, Royal Perth Hospital, University of Western Australia Medical School, Perth, \\ Australia, ${ }^{4}$ WA Centre for Health and Ageing, Centre for Medical Research, Perth, Australia
}

Corresponding Author: Leon Flicker, MBBS, PhD Department of Geriatric Medicine, Royal Perth Hospital, University of Western Australia Medical School, MRF Building, Level 6, Rear 50 Murray St, Perth WA 6000, Australia

Tel: +61-8-9224-0377

Fax: +61-8-9224-0364

E-mail: leon.flicker@uwa.edu.au

Received: December 6, 2017 Revised: December 22, 2017 Accepted: December 25, 2017
The Australian aged care system has evolved for $>50$ years to support frail older adults and allow them to make informed decisions about their care. Hospitals provide streamlined geriatric services from visits at the Emergency Department to discharges from acute and subacute geriatric care units. Moreover, nonhospital aged care services, including Transition Care Program, Commonwealth Home Support Program, Home Care Packages Program, and Residential Care (nursing home) are provided under the auspices of the Australian Government. These various specialized hospital and nonhospital services are integrated and coordinated by the multidisciplinary assessment team called ACAT (Aged Care Assessment Team). Korea does not have a similar amount of time to prepare a well-organized aged care system because of a rapidly increasing older population. The Korean government and aged care experts should exert vigorous efforts to improve the last journeys of the Korean older population.

Key Words: Australia, Health services for the aged, Homes for the aged, Home Care Services, Korea

\section{INTRODUCTION}

In 2016, approximately 3.7 million Australians (15\% of the population) were aged $>65$ years. ${ }^{1)}$ This proportion is slightly higher than in Korea; however, the growth rate of the aging population in Australia has been much slower than that in Korea. This has resulted in Australia having a longer period of time to establish an aged care system that meets its needs by developing multidisciplinary geriatric teams in the community and hospitals and, a nonhospital residential aged (longterm) care system.

Since the introduction of Long-Term Care Insurance (LTCI) in 2008, the Korean aged care system has shown a substantial quantitative growth. However, facing the extremely rapid growth of the older population, which no other country has previously experienced, the Korean aged care system needs to innovate and improve governance and quality of each component and the manner in which these components interact. During this time point, Korean aged care experts should conduct an in-depth review on the aged care systems of developed countries that have a better experience in manag- ing the aging population. Australia has a mixed public-private system in health and aged care, which is similar to that of Korea, and its performance has been reported as one of the best in the world. ${ }^{2)}$ The Australian and Korean aged care systems were substantially different. Therefore, in this review, we describe the Australian aged care system, from its history to the current system, including hospital-based multidisciplinary geriatric, community, and residential care, assessment processes, and other important components. We also suggest some potential learning points for the Korean aged care system.

\section{HISTORY OF AUSTRALIAN AGED CARE}

Until the mid-twentieth century, poor older adults had access to protected places, such as asylums outside the market economy in Australia; however, these facilities were far from generous. ${ }^{3)}$ The 1962 amendment to the National Health Act 1953 that granted the benefit of nursing homes marked the beginning of Federal Government involvement in aged care. The introduction of Government's nursing home benefit had an immediate and pronounced effects on the growth in the 
industry. In 1972, the National Health Act 1953 was amended to control admissions to nursing homes, to decrease the growth of nursing home places and their fees. ${ }^{4)}$ The introduction of multidisciplinary assessment services and the expansion of community care have changed the direction of aged care from residential to home care since the mid-1980s. ${ }^{5}$ )

In the early 1950s, influenced by the United Kingdom and its own demand, hospital-based geriatric rehabilitation units were founded in Melbourne and Newcastle. ${ }^{6}$ The Australian Association of Gerontology, established in 1962, consisted of members from a variety of disciplines concerned with health problems of later life. ${ }^{7)}$ Because of the need for specific skills in medicine, the doctors in this group decided to form the Australian Geriatrics Society, which later became the Australian \& New Zealand Society for Geriatric Medicine. The society currently has $>1,050$ members and $>220$ trainees. The society is devoted to the medical care and rehabilitation of older adults, community geriatrics, and education and research. ${ }^{8}$

\section{PRINCIPLES OF AUSTRALIAN AGED CARE}

In 2004, the Australian Health Ministers' Advisory Council's Care of Older Australians Working Group developed the National Action Plan for improving the care of older adults across the acute-aged care continuum, which proposed the following seven principles of Australian aged care $^{9)}$ :

- Principle 1: Older adults have access to an appropriate level of health and aged care services that match their changing needs.

- Principle 2: Services are shaped based on diverse needs of older adults.

- Principle 3: Avoidable hospital admissions or premature admissions to long-term residential aged care are prevented where possible.

- Principle 4: Older adults have access to transition care services within the acute-aged care continuum.

- Principle 5: The health and aged care system operate to deliver an integrated suite of services and care for older adults.

- Principle 6: The workforce involved in caring for older adults is skilled and responsive, and the number is sufficient to meet older adults's needs.

- Principle 7: Informal carers and family members are supported, and their contribution acknowledged.

\section{BIRD'S EYE VIEW OF THE CURRENT AUSTRALIAN AGED CARE}

Australia has a universal public health insurance program, Medicare, much like the National Health Insurance of Korea. Medicare, which is funded through tax revenue, provides free or subsidized access to primary and public hospital care.
Nationally, approximately 700 public hospitals (53\% of the total) are running nearly 60,300 beds (65\% of the total) in Australia. Private health insurance (PHI) is readily available and offers various choices of providers (particularly in private hospitals) and faster access for nonemergency services. Government policies encourage $\mathrm{PHI}$ enrollment through a tax rebate and penalty payment for high-income Australians not having PHI. Nearly half of the Australian population (47\%) had PHI to access care outside the public system in 2016. The Australian total health expenditures in 2014-2015 represented $10.0 \%$ of the gross domestic product (GDP), and twothirds of these expenditures (67.0\%) came from the government. Out-of-pocket payments accounted for $18 \%$ of the total health expenditures. ${ }^{10)}$ According to a report comparing the healthcare systems between eleven high-income countries, the Australian system ranked the second best in the overall performance and was top-ranked on administrative efficiency and healthcare outcomes. ${ }^{2)}$

Australia's nonhospital aged care system is governed by the Aged Care Act of 1997. The Act established the quality assurance framework for the provision of care and approval of service providers. The aged care system offers a continuum of care under 3 main types of service, Commonwealth Home Support, Home Care Packages, and residential care (nursing home). ${ }^{11)}$ The aged care sector provides services to 1.3 million Australians and generates annual revenues around approximately Australian dollar (AUD) 21.5 billion annual revenues, representing almost $1 \%$ of GDP. Approximately $5.2 \%$ of the population aged $>65$ years is housed in a permanent residential care. ${ }^{12)}$ Although a national long-term care insurance system is unavailable, the Australian Government provides financial support from tax revenues for Australian citizens and permanent residents to access adequate aged care services with affordable out-of-pocket payments. The total Australian Government expenditure on aged care in 2015-2016 was AUD 16.2 billion (approximately 75\% of total aged care expenditure). Table 1 summarizes the current status of Australian aged care. ${ }^{13)}$

Approximately half of Australian older adults had some degree of disabilities, but three-quarters reported their health as good or very good, ${ }^{1)}$ which is a far more favorable perception about their health status compared to that of Koreans. ${ }^{14)}$ Relatively healthy and independent Australian older adults manage their health with community health supports and primary care services provided by general practitioners. An older person who suffers acute medical illness or trauma, which cannot be managed at primary care level, visits the Emergency Departments (EDs) of acute hospitals. Patients who need admission are often managed in an acute geriatric unit. After acute geriatric care which commonly takes several days, some older patients may be transferred to subacute care units or hospitals for rehabilitation and multidisciplinary 
Table 1. The current status of Australian nonhospital aged care (2015-2016)

\begin{tabular}{lccr}
\hline \hline Variable & Home support* & Home care & Residential care \\
\hline No. of providers & 1,686 & 496 & 949 \\
No. of services & N/A & 2,099 & 2,669 \\
No. of places & N/A & 78,956 & 195,825 \\
No. of consumers & $>925,432$ & 88,875 & 234,931 \\
Governmental funding (AUD) & 2.2 billion & 1.5 billion & 11.4 billion \\
Consumer contribution (AUD) & N/A & 160 million & 4.5 billion \\
\hline
\end{tabular}

Values are presented as number.

AUD, Australian dollar; N/A, not available.

*Some data for home support are not presented here as reliable data are not available.

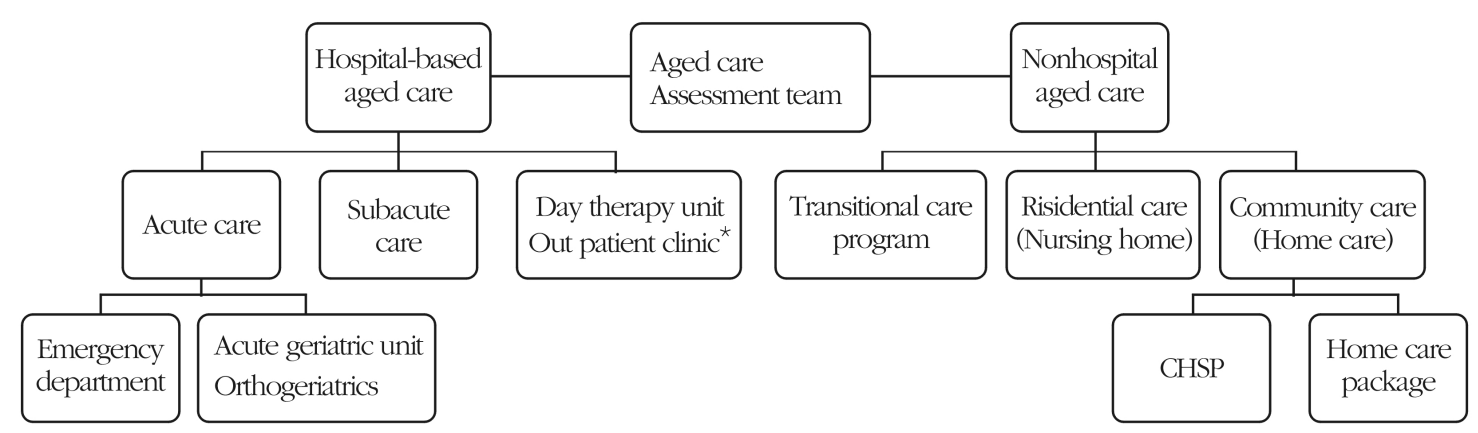

Fig. 1. Schematic diagram of the aged care system in Australia. Various specialized hospital and nonhospital services are coordinated by Aged Care Assessment Team. CHSP, Commonwealth Home Support Program. *Memory, fall, and incontinence clinic, etc.

team support if their functional ability is insufficient for safe discharge. In subacute care, rehabilitation is offered for 2-3 weeks, but may be longer if the situation demands. If functional recovery does not meet the rehabilitation goals decided by the multidisciplinary team for independent living, older adults may be candidates for nonhospital aged care services, such as transitional, community, or residential care. The eligibility for the nonhospital aged care is assessed by a multidisciplinary team called the Aged Care Assessment Team (ACAT) (Fig. 1).

\section{HOSPITAL-BASED AGED CARE}

\section{Acute care for older adults}

\section{1) Emergency Department}

EDs are the major entry points to hospital care for older adults. In Australia, patients aged $\geq 65$ years accounted for approximately $20 \%$ of all ED visits. ${ }^{15)}$ The 3 most common diagnoses for ED visits in the older adults were Pain in throat and Pain in chest, followed by Abdominal and pe/vic pain and Syncope and collapse (fainting) in 2013-2014. ${ }^{16}$ )

Interventions in the ED targeted toward older adults may be useful to minimize the risk of hospitalization as well as subsequent premature admissions to long-term residential aged care. ${ }^{17)}$ Because of this, the introduction of geriatric expertise to the management of older patients in ED has been recommended in Australia. ${ }^{18)}$ For example, Aged Care Services in Emergency Teams are operated to assess and support older adults who present to an ED in New South Wales. ${ }^{19)}$ In Western Australia (WA), a comprehensive care team in the ED consists of allied health personnel, such as physiotherapists and occupational therapists. They screen all geriatric admissions from the ED regardless of the presenting complaint. Furthermore, for patients who have geriatric syndromes and are not admitted, the team can make referrals to general physicians, appropriate specialist clinics (e.g., falls, memory, and incontinence clinic), and community ACAT team.

\section{2) Acute geriatric unit}

Acute geriatric care unit that provides early rehabilitation, early discharge planning, and a suitable environment for an older patient has been shown to be associated with fewer falls, less delirium, less functional decline, shorter length of hospital stay, and fewer discharges to nursing home and more to home. ${ }^{20)}$

Based on a national survey of inpatient geriatric services in Australia conducted in 2001, 151 hospitals (22\%) reported that they operated some form of hospital geriatric inpatient service and larger hospitals were more likely to run aged 
care inpatient services. ${ }^{21)}$ Currently, most of the tertiary hospitals in Australia operate independent acute geriatric units that provide patient-centered multifaceted services, including comprehensive geriatric assessment and care focusing on physical and mental health, cognition, medication review, functional ability, early rehabilitation, and early discharge planning consistent with the social situation. In the unit, a multidisciplinary team, usually consists of a geriatrician, specialized nurse, physiotherapist, occupational therapist, social worker, and/or nutritionist, cares for older patients in a coordinated manner. Patient care and discharge plans are frequently discussed and formulated in multidisciplinary team meetings.

\section{3) Orthogeriatrics (orthopedic-geriatric models of care)}

Orthogeriatrics is defined as the care of older orthopedic inpatients, mostly with hip fracture. Orthogeriatrics was developed as a subspecialty to address poor outcomes in patients with hip fracture by caring alongside orthopedic surgeons and with the support of a geriatric multidisciplinary team. ${ }^{22)}$ A Cochrane review reported that interdisciplinary rehabilitation for older adults with hip fracture would decrease mortality and hospital readmission compared with the usual care. ${ }^{23)}$ An Australian prospective study showed that the introduction of orthogeriatric service could reduce the mortality $(7.7 \%$ to $4.7 \%)$, postoperative morbidity $(71.0 \%$ to 49.5\%), and rehospitalization within 6 months associated with medical problems (28\% to $7.6 \%)$. ${ }^{24)}$ Based on this evidence, the Australian and New Zealand Guideline for Hip Fracture Care recommended an orthogeriatric model of care, involving a geriatrician in the preoperative optimization of patient care in surgical preparation, leading the postoperative medical care and coordinating the discharge planning process. ${ }^{25}$ To encourage this model, the Australian Commission on Safety and Quality in Health Care has posted the orthogeriatric model as one of the hip fracture care standards. ${ }^{26)}$

\section{Subacute care}

The Australian Institute of Health and Welfare defined subacute care as specialized multidisciplinary care in which the primary goals are optimization of the patient's functioning and quality of life. Subacute care is classified into the four defined subtypes; rehabilitation, palliative care, geriatric evaluation and management (GEM) and psychogeriatric care. ${ }^{27)}$ Some services such as stroke rehabilitation and palliative care are essential parts of aged care, but this review describes subacute care focusing on GEM and psychogeriatric care that are rarely provided in the Korean aged care setting.

\section{1) Geriatric evaluation and management}

A GEM unit provides continued medical and multidisci- plinary care for inpatients deconditioned by acute medical illness and/or geriatric syndromes. A typical GEM team is composed of a geriatrician, clinical nurse specialist, social worker, and specialists from fields such as occupational and physical therapy, nutrition, pharmacy, audiology, and psychology. GEM units are typically separate hospital wards that have been redesigned to facilitate care for geriatric patients. Multidisciplinary team rounds and patient-centered team conferences are hallmarks of GEM. ${ }^{28)}$ Most patients in the GEM unit are transferred from acute care units after stabilization of acute illness. The activities and members of the GEM team are not much different from the multidisciplinary team in the acute geriatric care unit; however, their goal is more focused on functional restoration and discharge planning rather than treatment of acute illness itself. Randomized clinical trials showed that inpatient GEM service can reduce mortality and functional decline of frail older patients without increasing the costs. ${ }^{29,30)} \mathrm{A}$ meta-analysis revealed that GEM service increased patients' likelihood of being alive and in their own homes after an emergency admission to hospital. ${ }^{311}$ There are various GEM care models around Australia. Victoria and WA have large inpatient GEM programs. Otherwise, New South Wales primarily provides GEM in outpatient settings. Average lengths of stay in GEM units varied from 14.3 to 23.6 days by care type and states. ${ }^{27}$

\section{2) Psychogeriatric unit}

Psychogeriatric disorders include psychiatric conditions that predate the aging process and mental disorders that develop for the first time in later life, for example, dementia, late-onset schizophrenia, or depression. ${ }^{32)}$ Mental health services for older adults should be an integral part of the whole aged care system to achieve high-quality care. Older patients who have certain severe symptoms such as dementia with severe behavioral and psychological symptoms, severe depression, and psychosis with suicidal tendency are best managed in a specialist psychogeriatric unit. However, psychogeriatric care is not applicable if the primary concern is less acute symptoms, and the primary clinical purpose is to improve the functional status, behavior, and quality of life of an older patient with significant psychiatric or behavioral disturbance. ${ }^{26)}$ Although psychogeriatric care models around Australia still lacks consistency until now, a care model with collocated GEM and psychogeriatric units and close collaboration within the same hospital is an effective and efficient method to manage older patients with multiple comorbid conditions.

\section{Day therapy unit (DTU) and outpatient geriatric clinic}

The purpose of DTU services is to deliver non-admitted subacute care to eligible patients in the ambulatory setting. 
DTU services have been well developed in WA compared with other states and territories. The demand for communitybased subacute care in WA was high because of the historical concentration of healthcare resources in acute care service provision, particularly within the metropolitan area. This review has described the DTU and geriatric clinics in WA based on the WA Health Day Therapy Unit Service Delivery Guidelines 2014. ${ }^{33)}$

The services provided by DTUs in WA include rehabilitation, GEM clinics, nursing, and allied health assessment and therapy. Rehabilitation offers individualized and time-limited assessment and therapy sessions by medical, nursing, and allied health professionals. Its aim was to improve the functional capacity, and the care is delivered according to a tailored care plan based on functional goals discussed with the patient and their carers. GEM clinics provide specialist assessment, diagnosis, intervention, management, education, advice, and support mainly to older patients with geriatric syndromes and complex medical care. Specialty clinics may include:

- Geriatric medical clinics: for older patients with complex healthcare issues

- Falls clinics: for patients with falls, mobility and balance problems

- Memory clinics: for patients with cognitive complaints or dementia

- Continence clinics: for patients with bladder and/or bowel function difficulties

- Other specific clinics such as Parkinson disease, stroke, and osteoporosis

Costs were not charged to patients; however, DTU services require a referral from general practitioners, hospitals, or EDs. Currently, 13 DTUs are running in WA, 8 in the metropolitan area and 5 outside the Perth area. ${ }^{34)}$ Demand for DTU services is expected to increase in Australia because of increased pressure on inpatient resources, demographic changes, and benefits of evidence-based care provided in the community.

\section{AGED CARE ASSESSMENT TEAM}

ACATs are teams who assess the needs of frail older adults and help them and their carers access appropriate levels of support, including residential care, home care packages, transitional care, and respite care. ${ }^{13)}$ ACAT consists of doctors (usually geriatricians), nurses, social workers, physiotherapists, occupational therapists, and other health professionals such as speech pathologists and dieticians. ${ }^{35)}$

If some older adults are no longer able to manage at home without basic assistance, they can apply for an assessment to local ACAT for free. This is managed by a central regional center where options for less-intensive community supports may be offered. If an ACAT assessment is deemed appropriate, a local ACAT member visits the older adults in their home or hospital, if currently admitted. Some ACAT members may have over-arching responsibilities and work in hospitals, which enable more immediate assessment for hospitalized older patients. The assessment includes social, medical, physical, and psychological domains. After the assessment, the ACAT provides a report regarding the outcome of the evaluation and the services eligible for older adults, with a copy provided to the client. ${ }^{35)}$

These ACATs, which may be integrated into regional geriatric services, operate as "gatekeepers" to expensive resource items, such as residential care and home care packages. They also serve as central referral sources for GEM unit, rehabilitation, community services, psychogeriatric services, and other specialized geriatric clinics. The ACAT service, which costs Australian and State Governments an estimated amount of AUD 114 million a year, is regarded as a cost-effective way of safeguarding the integrity of Australian Government on the total aged care expenditure (AUD 18.6 billion in 2017-2018). ${ }^{13)}$ Approximately 200,000 ACAT assessments have been performed every year by the 80 ACATs, which operate in all Australian states and territories. Since the early 2016, all ACATs transitioned to using the My Aged Care system to conduct assessments and approvals and make referrals to services or service provider waitlists. Aged care service providers can also receive these referrals through the My Aged Care system. ${ }^{36)}$

\section{NONHOSPITAL AGED CARE}

The Australian aged care system offers a continuum of nonhospital aged care under 3 main types of service, commonwealth home support, home care packages, and residential care. Some types of flexible care such as Transition Care Program (TCP), are also available. Nonhospital aged care provided 199,449 residential care, 79,819 home care, and 4,000 TCP places in 2016.

\section{Transition Care Program}

Transitional care refers to a broad range of services and environments designed to promote the safe and timely passage of patients between levels of health care and across care settings. ${ }^{37)}$ However, TCP in this review is defined as a short-term care service in Australia, which focuses on optimizing the function and promoting independence of older adults after a hospital stay to prevent early residential care admission.

In Australia, the TCP was introduced in 2005 by the Aged Care Act $1997^{38)}$ It is goal-oriented, time-limited, and therapy-focused care for older adults at interface of the acute/ subacute and residential aged care sectors. It targets older adults at the conclusion of a hospital episode who require 
longer time and support in a nonhospital environment to complete their restorative process, optimize their functional capacity, and finalize and access their long-term care arrangements either at their own home or permanent residence. ${ }^{39)}$

The TCP service includes low-intensity therapy services, nursing support, and personal care services. Low-intensity therapy services may include physiotherapy, occupational therapy, dietetics, speech therapy, podiatry, counseling, and social worker service. The personally tailored services are provided by approved providers in the recipient's home, daycare, or residential care setting based on an individual's circumstances. ${ }^{35)}$

To access transition care, a patient must first be assessed and approved by ACAT. Usually, an ACAT member who holds an additional position in a hospital as a social worker performs the assessment and arrangement for the proper facility. The TCP can be provided for up to 12 weeks, which can possibly extend to 18 weeks if assessed as requiring an extra time of therapeutic care. The average duration of a transition care episode was 7.5 weeks. ${ }^{39)}$ A total of 24,665 people received transition care in 2015-2016. ${ }^{36)}$ The average cost of residential and home-based TCP is estimated at AUD 236 and AUD 86 per day, respectively, in 2006-2007. ${ }^{38)}$ The maximum daily fee charged for care recipients is approximately AUD 50 and 10 for care delivered in residential care settings or care provided at home, respectively. ${ }^{35)}$

The national evaluation reported that TCP could prevent hospital readmissions and transfers to residential aged care. ${ }^{35)}$ A prospective study showed that TCP was associated with the maintenance and improvement in the quality of life of frail older adults. ${ }^{40)}$ With the success in TCP, the Australian Government is building a new flexible aged care type, Short Term Restorative Care, which is available to temporarily dependent older people that have not being in a hospital. ${ }^{41)}$

\section{Commonwealth Home Support Program}

Home Support Program provides entry-level support services for frail, older adults aged $\geq 65$ years. In 2015, the Commonwealth Home Support Program (CHSP) was implemented, combining the previous Commonwealth Home and Community Care program (HACC), the National Respite for Carers Program, Day Therapy Centers program, and Assistance with Care and Housing for the Aged. ${ }^{13)}$ This program provides services focused on supporting older people to undertake tasks of daily living, which enables these people to be more independent at home and in the community, to reduce early admission to residential care. Services could be provided on an on-going or episodic basis, depending on their needs.

The CHSP provides a range of services as follows:

- Transport

- Social support
- Assistance with food preparation at home and delivery of meals

- Nursing and personal care

- Allied health services like podiatry, physiotherapy, and speech pathology

- Domestic assistance including help with cleaning, washing, and shopping

- Support for carers including respite services

- Home maintenance and modifications

The Australian Government has established thirteen Regional Assessment Services to deliver regional level assessments of older people seeking the services provided under the CHSP. About 1,700 service providers offered the home support services to more than 925,000 older Australians nationally in 2015-2016. The CHSP is run as a governmental grant program. The federal and state Government expenditure for the Home Support program in 2015-2016 was AUD 2.2 billion (Table 1). The Australian Government released the Client Contribution Framework for the future financial sustainability of the CHSP in 2015. The Framework outlines the principles providers need to adopt in setting and implementing their own client contribution policy. ${ }^{36)}$

\section{Home Care Packages Program}

The Home Care Packages Program provides a subsidy towards a package of care, services, and case management for those who have higher care needs than the level of care offered by the CHSP. The four package levels are structured as follows:

- Level 1 -to support people with basic care needs

- Level 2-to support people with low-level care needs

- Level 3-to support people with intermediate care needs

- Level 4-to support people with high care needs

Each level of home care package provides a different amount of subsidy. This amount is paid to approved home care providers chosen by the clients. The subsidy can be used for:

- Personal services: bathing, toileting, dressing, and mobility assistance

- Nutrition, hydration, meal preparation, and diet

- Continence management

- Aids for mobility and safety

- Nursing and allied health services

- Transport and personal assistance

- Management of skin integrity

Separate supplements for oxygen therapy, enteral feeding, and dementia care were also available in the home care packages,

To access a home care package, ACAT assessment is mandatory. After the assessment, the ACAT make a formal decision about care needs, eligibility to receive Home Care Pac- 
kage, and the level of Home Care Package. They also give client information on home care services in their area and help clients access the care they need. ${ }^{42)}$

Approximately 500 service providers delivered the Home Care Packages service to 88,875 older Australians nationally in 2015-2016. The Australian Government expenditure for the service was approximately AUD 1.5 billion (Table 1). Consumers who have taken up a Home Care Package are required to pay a basic daily fee that is equal to $17.5 \%$ of the single rate of the basic age pension (AUD 9.93 as of June 30, 2016) and an income-tested care fee. The latter is only paid by those assessed as having sufficient income to contribute to the cost of their care. The mean annual cost of the Home Care Package service per client was approximately AUD 21,000 in $2015-2016 .{ }^{36)}$

\section{Residential care (nursing home)}

Residential care is for older adults who can no longer live at home for various reasons, including personal-care (help with the activities of daily living such as dressing, eating, and bathing), accommodation, support (cleaning, laundry, and meals), and other allied health services, such as physiotherapy or podiatry. ${ }^{36)}$

Residential care facilities provide accommodation ranging from single rooms with bathroom to shared places based on the accommodation fee. Most of the nursing homes have their own secure garden, and some of them provide secure dementia unit and specialized palliative care. Some nursing homes offer "extra services" including a higher standard of accommodation and entertainment (e.g., Internet or satellite TV), food/beverage choices (e.g., wines or beer), and special therapies (e.g., massage or aromatherapy) at an additional cost for the residents. Fees for "extra services" set by the provider and approved by the Australian Government. ${ }^{35)}$

Entry into a government funded residential care requires approval by an ACAT. A total of 234,931 older adults received residential care at any time in 2015-2016, and 175,989 people received permanent residential care. Approximately $70 \%$ of the residents were women. The average age (on entry) of residents was 82.0 for men and 84.5 for women, and the average completed length of stay was 34.7 months with $<1 \%$ of permanent residents transferring to another location before death. Approximately $50 \%$ of nursing home residents were diagnosed with dementia in Australia, but there are questions about the validity of this with many concerned that this is a major underestimate. ${ }^{36)}$

The average annual level of Australian Government payments for residential care was AUD 63,400 per care recipient in 2015-2016. The payment is composed of a basic subsidy and some compliments. The basic subsidy is determined by the resident's classification under the Aged Care Funding
Instrument, and the supplements pay for oxygen therapy, enteral feeding or accommodation for some recipients. In total, the Australian Government's expenditure for residential care services was about AUD 11.4 billion (Table 1). ${ }^{13)}$

Nursing homes charge a range of fees to cover the cost of care, accommodation, and living expenses of the residents. These fees are separate but related to the amount of government subsidy and can vary enormously between facilities and from resident to resident according to their income and assets. All residents in nursing homes can be asked to pay a basic daily fee, which is $85 \%$ of the basic age pension (AUD 48.25 per day in 2017). Also, residents can be asked to pay an additional income and assets tested contribution to their care fee and accommodation payment. Extra service fees can be charged according to the services provided by each facility. An approved provider may also charge a resident for additional lifestyle services (e.g., hairdressing, manicure and pedicure), which the resident has asked the provider to provide. The total cost of residential care per resident per day in 2015-2016 was AUD 243.4 and about 29\% of the price is paid by residents. ${ }^{13)}$

Residential respite provides short-term care on a planned or emergency basis in nursing homes to people who have been assessed and approved to receive it. Care recipients are entitled to 63 days of subsidized respite care in a year; however, recipients may apply to an ACAT for extensions of up to 21 days for various reasons. ${ }^{35}$

\section{OTHERS}

\section{Informed access to aged care}

The Australian Government provides useful information and comprehensive, needs-based assessment services to ensure older adults and their carers are fully informed and their needs are adequately assessed. My Aged Care is the entry point for older Australians seeking aged care services. My Aged Care assists older adults, their families, and carers to access information on aged care, receive referrals for assessments, and identify commonwealth funded aged care services in their local area. In 2015-2016, the My Aged Care contact center answered 690,544 calls and received 293,718 pieces of web and fax correspondence, whereas the website had a total of 3,009,377 visits. The department also disseminates printed material on aged care to consumers, care providers, health professionals, and the general community. ${ }^{36)}$ The website of My Aged Care is https://www.myagedcare.gov.au/.

\section{Informal carer support}

Informal care is provided by family, friends, and neighbors and is assumed to cover the majority of all care for older 
adults. In 2012, 2.7 million Australian people were identified as informal carers to old or disabled people, with 400,000 as primary carers to those aged $\geq 65$ years. Informal care determines the level, composition, and cost of formal aged care. The value of unpaid care was estimated to be worth AUD 40 billion in Australia in 2010. However, carers work less and are more likely to be poor and suffer mental health problems. ${ }^{43)}$

The Australian Government's commitment for the informal carer is well expressed in the Action Plan for National Carer Strategy (2011-2014). The report first sets priorities for action on the six areas below. ${ }^{44)}$

- Recognition and respect

- Information and access

- Economic security

- Services for carers

- Education and training

- Health and well-being

Australia's Fair Work Act 2009 has recently been amended to allow carers to request flexible arrangements on reasonable business grounds and 10 days of paid leave.

There is also a range of direct services to support carers. These include complimentary to the informal care (e.g., HACC program), a temporary substitute (e.g., respite at home, in a day center, or in a residential facility for up to 63 days a year), social and emotional help (e.g., the National Carer Counselling Program), educational programs (e.g., Dementia Education and Training for Carers), and information and coordination services (e.g., Commonwealth Respite and Carelink Centers).

Finally, the Australian Government offers financial support to carers. The financial support consists of a Carer Allowance (a supplement to cover some costs of caring) and Carer Payment (for cohabiting carers who were unable to work as a result of caring). The Australian Government expenditure to financially support the carers was approximately AUD 1.8 billion. ${ }^{43)}$

\section{Dementia in Australia}

Dementia is the major issue faced by Australian aged care as well as other developed countries. This is because overall dementia prevalence is increasing as older people live longer, and there are no effective means of cure although the risk of dementia may be able to be decreased. ${ }^{45)}$ Dementia has been the second leading cause of death in Australia and became the leading cause of death among women in 2016. ${ }^{46)}$ Managing dementia should be the responsibility of three main groups: families, care providers, and the whole community.

Dementia Australia, which has evolved from Alzheimer's Australia, delivers national dementia programs and services funded by the Australian Government as follows ${ }^{47}$ :
- National Dementia Helpline

- Early intervention programs such Living with Memory Loss

- National Younger Onset Dementia Key Worker program

- Dementia and Memory Community Centres

- Counselling

- Carer support groups

- Education for family carers

- Public awareness activities

Dementia Training Australia (DTA) is a Government funded consortium of experts in dementia care and workforce training. DTA provides dementia-specific training to aged care, health care professionals, undergraduate trainees, and community service providers through a diverse array of online and offline programs. ${ }^{48)}$

\section{Quality and Regulation}

The Australian Government's approach to quality and regulation focus on providers' responsibility for providing, maintaining and improving services. To receive funding from the Australian Government an aged care service must be operated by an approved organization. ${ }^{36)}$

The Australian Aged Care Quality Agency is an independent agency responsible for quality monitoring of aged care providers. The Quality Agency accredits Australian Governmentsubsidized nursing homes. ${ }^{49)}$ The accreditation standards cover areas such as management, staffing, health and personal care, resident lifestyle, living environment, catering, cleaning, continuous improvement, and safety and security. Nursing homes can be accredited by the Quality Agency for up to 3 years. ${ }^{50)}$ The agency also conducts quality reviews of community care services. Their activities include audits, contact assessment, and unannounced visits. ${ }^{36)}$

The Aged Care Complaints Commissioner take over responsibility for the management of complaints about Australian Government-funded aged care. Their annual report showed that a total of 4,617 complaints were finalized in 2016-2017, and most complaints were about residential care. ${ }^{51)}$ In 2016, the Aged Care Quality Indicator Program posted 3 clinical indicators: unplanned weight loss, pressure injuries, and physical restraint. Quality indicator data will be published on the My Aged Care website. ${ }^{36)}$

\section{IMPLICATIONS FOR KOREAN AGED CARE}

The Korean aged care has shown substantial quantitative growth and has reduced the care burden for a lot of families who live with frail older adults since the introduction of LTCI in 2008. In 2016, >8,000 providers were supplying various aged care services in Korea. More than 5,000 providers operated 192,370 residential care beds, and another 3,000 providers 
offered home-based services, such as home care, home nursing, day care, respite care, and home bathing. ${ }^{52)}$ In addition, a total of 1,300 long-term care hospitals were operating 214,478 beds in $2014,{ }^{53)}$ and the health and functional status of patients in long-term care hospitals are known to be the same from those of the nursing home residents. ${ }^{54)}$

Although the absolute quantity of aged care service may not be deficient, several problems were encountered in the Korean aged care, such as its low-quality system, lack of coordination, and absence of long-term plans. The most serious problem is the fact that the Korean government has not been able to develop a long-term blueprint for aged care. The Australian government has an independent Minister of Aging and Aged Care and an Australian Aged Care Quality Agency under the Department of Health. Moreover, several governmental and non-governmental expert groups provide high-quality reports about critical issues in aged care, ${ }^{13,36,43)}$ and they are used to help develop and drive government policies and financial operations. The Australian Government manages the supply of aged care by specifying a national provision target of subsidized operational aged care places for every 1,000 people aged $\geq 70$ years, known as the aged care provision ratio. In 2015-2016, this figure was 113.2. The aged care provision ratio is estimated to increase to 125 by $2021-2022$. As the number of places increases, the target for Home Care Packages will increase from 27 to 45 , and the residential care target will reduce from 86 to 78 following the expansion and strengthening of community care services. $^{36)}$

More and more older adults want to keep living in their own homes and communities for as long as possible in Korea as well as in Australia. However, the aged care supply has been mainly focused on residential care in Korea, and the effort to expand and diversify home-based services and improve its quality has been insufficient. Although the statistical data about informal carers are limited in Korea, a majority of Korean frail older adults have been cared by informal carers, usually their family members. However, the support for informal carers is not prominent in the Korean aged care system, except for cash payments for residents in remote areas and some counseling services which are still on trial. Many developed countries including Australia have provided a financial support, opportunity for flexible working and paid/unpaid leave, education, respite care, as well as counseling to support informal carers. ${ }^{43)}$ In Korea, strengthening both home-based care and supports for informal carers is essential for the development of community-based aged care system.

Another important aspect is that many Korean older adults who have temporary functional deterioration caused by acute illness are likely to go to nursing homes or long-term care hospitals because of the lack of subacute care in the Korean healthcare system. This results in the absence of short-term rehabilitation and multidisciplinary team interventions. Most of the long-term care hospitals that have introduced subacute care have not taken the role of discharging older patients to their own homes because of very low fixed payment by the National Health Insurance and the competition to lower patient's own payment between long-term care hospitals. Therefore, many long-term care hospitals are taking over roles similar to that of the nursing homes. In this situation, functions of long-term care hospitals should be immediately defined to transform them into geriatric hospitals specializing in rehabilitation of frail older adults, palliative care, psychogeriatric care, or maintenance care for patients who have high medical care demand.

Lastly, workforce specializing in aged care, such as geriatricians, special geriatric nurses, and allied health professionals including physiotherapists and occupational therapists, is limited in Korea. ${ }^{55)}$ To provide a sufficient number of skilled health and aged care workers, education and training programs that align with Korean aged care needs should be developed. In addition, the current assessment process in determining the eligibility for LTCI service should be transformed into multidisciplinary assessment like those of the Australian ACAT which functions as a coordinator in aged care continuum from hospital to community.

\section{CONCLUSION}

The Australian aged care system has evolved for $>50$ years to support frail older adults and allow them to make informed decisions about their care. The current system is composed of various specialized hospital and nonhospital services, which are coordinated by multidisciplinary assessment teams. Korea does not have a similar amount of time to prepare a well-organized aged care system because of a rapidly increasing older population. Vigorous efforts of the Korean government and aged care experts are urgently required to improve the last journeys of the Korean older population.

Conflicts of Interest Disclosures: The researchers claim to have no conflicts of interest.

\section{Acknowledgments}

The authors greatly appreciate Desna Grundy for the introduction of the Australian aged care system and arranging visits to TCP and residential care facilities.

\section{REFERENCES}

1. AIHW. Older Australia at a glance [Internet]. Canberra: Australian Institute of Health and Welfare; c2017. [cited 2017 Oct 8]. Available from: https://www.aihw.gov.au/reports/older-people/ 
older-australia-at-a-glance/related-material-1.

2. Eric CS, Dana OS, David S, Arnav S, Michelle MD. Mirror, Mirror 2017: International Comparison Reflects Flaws and Opportunities for Better U.S. Health Care. New York: The Commonwealth Fund; 2017.

3. Dickey B. Care for the aged poor in Australia, 1788-1914. Community Health Stud 1983;7:247-55.

4. Department of the Parliamentary Library. Residential care for the aged: an overview of government policy from 1962 to 1993. Canberra: Department of the Parliamentary Library; 1993.

5. Bruen W. Aged care in Australia: past, present and future. Australas J Ageing 2005;24:130-3.

6. Lefroy RB. Origins and development of geriatric medicine in Australia. Intern Med J 2001;31:422-5.

7. AAG: Our History [Internet]. St Kilda: Australian Association of Gerontology; c2017 [cited 2017 Oct 5]. Available from: https://www.aag.asn.au/about-us/our-history.

8. ANZSGM. About ANZSGM [Internet]. Sydney (Australia): Australian \& New Zealand Society for Geriatric Medicine; c2017 [cited 2017 Oct 5]. Available from: http://www.anzsgm.org/ about.asp.

9. AHMAC Care of Older Australians Working Group. The national action plan for improving the care of older people across the acute aged continuum - from hospital to home. Canberra (Australia): Department of Health and Ageing; 2004.

10. Glover L. International Health Care System Profiles, The Australian Health Care System [Internet]. New York: The Commonwealth Fund; c2017 [cited 2017 Dec 19]. Available from: http://international.commonwealthfund.org/countries/australia.

11. OECD. A good life in old age? Monitoring and improving quality in long-term care. Paris: OECD Publishing; 2013.

12. ABS. Census of population and housing: reflecting Australia stories from the census, ageing population, 2016 [Internet]. Canberra (Australia): Australian Bureau of Statistics; c2017 [cited 22 Dec 2017]. Available from: http://www.abs.gov.au/ausstats/ abs@.nsf/Lookup/by\%20Subject/2071.0 2016 Main\%20Feat ures $\sim$ Ageing\%20Population $\sim 14$.

13. Aged Care Financing Authority. Annual report on the funding and financing of the aged care sector - 2017. Canberra (Australia): Aged Care Financing; 2017.

14. Ministry of Health and Welfare of Korea, Korea Centers for Disease Control and Prevention. Korea Health Statistics 2015: Korea National Health and Nutrition Examination Survey (KNHANES VI-3). Cheongju: Ministry of Health and Welfare of Korea; 2016.

15. Australian Institute of Health and Welfare. Emergency department care 2015-16: Australian hospital statistics. Health services series no. 72. Cat. no. HSE 182. Canberra (Australia): AIHW; 2016.

16. Australian Institute of Health and Welfare. Australia's health 2016. Australia's health series no. 15. Cat. no. AUS 199. Canberra (Australia): AIHW; 2016.

17. Karam G, Radden Z, Berall LE, Cheng C, Gruneir A. Efficacy of emergency department-based interventions designed to reduce repeat visits and other adverse outcomes for older patients after discharge: a systematic review. Geriatr Gerontol Int 2015;15: 1107-17.

18. Aged Care Network. Model of care for the older person in
Western Australia. Perth (Australia): Department of Health; 2007.

19. NSW Government, Ministry of Health. NSW aged care services in emergency teams practice guidelines. Sydney (Australia): Ministry of Health; 2014.

20. Fox MT, Persaud M, Maimets I, O'Brien K, Brooks D, Tregunno $\mathrm{D}$, et al. Effectiveness of acute geriatric unit care using acute care for elders components: a systematic review and meta-analysis. J Am Geriatr Soc 2012;60:2237-45.

21. Gray L, Moore K, Smith R, Dorevitch M. Supply of inpatient geriatric medical services in Australia. Intern Med J 2007;37: 270-3.

22. Hannah H, Rachel H, Anita R, Ali A. Orthogeriatrics [Internet]. East Sussex (UK): GM; c2013-2017 [cited 16 Oct 2017]. Available from: https://www.gmjournal.co.uk/orthogeriatrics.

23. Handoll HH, Cameron ID, Mak JC, Finnegan TP. Multidisciplinary rehabilitation for older people with hip fractures. Cochrane Database Syst Rev 2009;(4):CD007125. https:// doi.org/10.1002/14651858.CD007125.pub2.

24. Fisher AA, Davis MW, Rubenach SE, Sivakumaran S, Smith PN, Budge MM. Outcomes for older patients with hip fractures: the impact of orthopedic and geriatric medicine cocare. J Orthop Trauma 2006;20:172-8.

25. Australian and New Zealand Hip Fracture Registry (ANZHFR) Steering Group. Australian and New Zealand Guideline for hip fracture care: improving outcomes in hip fracture management of adults. Sydney (Australia): Australian and New Zealand Hip Fracture Registry Steering Group; 2014.

26. Australian Commission on Safety and Quality in Health Care. Hip fracture care clinical care standard. Sydney (Australia): ACSQHC; 2016.

27. Australian Institute of Health and Welfare. Development of nationally consistent subacute and non-acute admitted patient care data definitions and guidelines. Cat. no. HSE 135. Canberra (Australia): AIHW; 2013.

28. Agostini JV, Baker DI, Bogardus ST. Geriatric evaluation and management units for hospitalized patients [Internet]. Rockville (MD): Department of Health and Human Services; c2001-2017 [cited 2017 Oct 19]. Available from: http://archive.ahrq.gov/ clinic/ptsafety/chap30.htm.

29. Cohen HJ, Feussner JR, Weinberger M, Carnes M, Hamdy RC, Hsieh F, et al. A controlled trial of inpatient and outpatient geriatric evaluation and management. N Engl J Med 2002;346: 905-12.

30. Rubenstein LZ, Josephson KR, Wieland GD, English PA, Sayre JA, Kane RL. Effectiveness of a geriatric evaluation unit. A randomized clinical trial. N Engl J Med 1984;311:1664-70.

31. Ellis G, Whitehead MA, Robinson D, O'Neill D, Langhorne P. Comprehensive geriatric assessment for older adults admitted to hospital: meta-analysis of randomised controlled trials. BMJ 2011;343:d6553.

32. Department of Health and Ageing. Report to the Minister for Ageing on residential care and people with psychogeriatric disorders. Canberra (Australia): DoHA; 2008.

33. WA Department of Health. WA health day therapy unit service delivery guidelines 2014. Perth (Australia): WA Department of Health; 2014.

34. WA Department of Health. Healthy WA, Day therapy units subacute care [Internet]. Perth (Australia): WA Department of 
Health; c2017 [cited 2017 Oct 23]. Available from: http:// healthywa.wa.gov.au/Articles/A_E/Day-therapy-units-subacute-care.

35. DPS Publishing. DPS guide to aged care WESTERN AUSTRALIA 2017. Adelaide (Australia): DPS Publishing Pty Ltd.; 2016.

36. The government of Australia, Department of Health. 2015-16 Report on the operation of the aged care act 1997. Canberra (Australia): Department of Health; 2016.

37. Naylor M, Keating SA. Transitional care. Am J Nurs 2008; 108(9 Suppl):58-63.

38. Transition Care Working Group. National evaluation of the transition care program. Canberra (Australia): Department of Health; 2008.

39. Australian Government, Department of Health. Transition care programme guidelines. Canberra (Australia): Department of Health; 2015.

40. Comans TA, Peel NM, Gray LC, Scuffham PA. Quality of life of older frail persons receiving a post-discharge program. Health Qual Life Outcomes 2013;11:58.

41. Australian Government, Department of Health. Short-term restorative care programme [Internet]. Canberra (Australia): Department of Health; c2017 [cited 30 Oct 2017]. Available from: https://agedcare.health.gov.au/programs-services/flexible-care/ short-term-restorative-care-programme.

42. Australian Government, Department of Health. Your guide to home care package services. Canberra: Department of Health; 2017.

43. CEPAR. Aged care in Australia: part I - policy, demand and funding. Sydney (Australia): Centre of Excellence in Population Ageing Research; 2014.

44. Australian Government. National carer strategy - action plan (2011-2014). Canberra (Australia): Department of Families H, Community Services and Indigenous Affairs; 2011.

45. Wu YT, Beiser AS, Breteler MMB, Fratiglioni L, Helmer C, Hendrie HC, et al. The changing prevalence and incidence of dementia over time - current evidence. Nat Rev Neurol 2017; 13:327-39.

46. ABS. Causes of Death, Australia, 2016. Canberra (Australia): Australian Bureau of Statistics; 2017.

47. Dementia Australia. Dementia Australia [Internet]. Canberra (Australia): Dementia Australia; c2017 [cited 15 Nov 2017]. Available from: https://www.dementia.org.au/about-us/dementia-australia.

48. Dementia Training Australia. About dementia training Australia [Internet]. Wollongong, DC: Dementia Training Australia; c2017 [cited 15 Nov 2017]. Available from: https://www.demen tiatrainingaustralia.com.au/about-dta/.

49. Australian Aged Care Quality Agency. Welcome to the Australian Aged Care Quality Agency [Internet]. Canberra (Australia): Australian Aged Care Quality Agency; c2017 [cited 15 Nov 2017]. Available from: https://www.aacqa.gov.au/.

50. My agedcare. Accreditation standards [Internet]. Canberra (Australia): My agedcare; c2017 [cited 15 Nov 2017]. Available from: https://www.myagedcare.gov.au/quality-and-complaints/ accreditation-standards.

51. Aged Care Complaints Commissioner. Aged care complaints commissioner annual report 2016-17. Canberra (Australia): Aged Care Complaints Commissioner; 2017.

52. Ministry of Health and Welfare of Korea. The current status of aged welfare facilities in 2017. Sejong: Ministry of Health and Welfare; 2017.

53. KOSIS. Hospitals and the number of beds [Internet]. Daejeon: Korean Statistical Information Service; c2014-2017 [cited 11 Oct 2017]. Available from: http://kosis.kr/statHtml/statHtml. do?orgId=110\&tblId=DT_11001N_2013_A042\#.

54. Jeon B, Kwon S. Health and long-term care systems for older people in the republic of Korea: policy challenges and lessons. Health Syst Reform 2017;3:214-23.

55. Choi H. Present and Future of Korean Geriatrics. J Korean Geriatr Soc 2011;15:71-9. 